\title{
Size at birth and later blood pressure
}

\author{
R Morley, G Lister, C Leeson-Payne, A Lucas
}

\begin{abstract}
Adults who were small at birth have been reported to have higher systolic blood pressure and risk of ischaemic heart disease in later life. Conversely, in 616 subjects of less than 34 weeks' gestation and $1850 \mathrm{~g}$ birth weight, systolic and diastolic blood pressures at 7.5 to 8 years of age decreased with decreasing weight for gestational age and were not related to birth weight. These data do not support the view that fetal growth retardation before 34 weeks programmes for increased blood pressure in later life. (Arch Dis Child 1994; 70: 536-537)
\end{abstract}

There has been considerable interest in the possibility that prenatal events could influence blood pressure in adult life. Adults who were small at birth have been reported to have higher systolic blood pressure ${ }^{12}$ and increased risk of death from ischaemic heart disease. ${ }^{2}$

A relation between low birth weight and higher blood pressure has also been reported in children $^{13}$ and Law et al ${ }^{4}$ suggested that low weight or head size in relation to length at birth were better markers for higher systolic blood pressure at 4 years of age.

We have been following up a large cohort of children weighing less than $1850 \mathrm{~g}$ at birth, most recently at $7 \cdot 5$ to 8 years of age when systolic and diastolic blood pressure were recorded. We have tested the hypothesis that size and size for gestational age at birth programme blood pressure in childhood.

\section{Methods}

Weight (using Soehnle digital scales), mid upper arm circumference, and systolic and diastolic blood pressure were measured by RM, GL, and CL-P in 616 children aged 7.5 to 8 (median $7 \cdot 6$ ) years who had been enrolled in multicentre randomised trials ${ }^{5}$ and born before 34 weeks' gestation (median 30, minimum 24 weeks) weighing less than $1850 \mathrm{~g}$ (median 1364, minimum $663 \mathrm{~g}$ ).

In $448(73 \%)$ children an automated blood pressure measuring device, the Accutor (Datascope Ltd) was used. When two
Accutors were unavailable a standard sphygmomanometer was used; diastolic blood pressure was recorded as the fourth Korotkoff sound. Cuff size was appropriate for mid arm circumference and the child was seated with the cuff on the left upper arm. Blood pressure was measured three times and a mean of the last two values used in analyses.

Birth anthropometry was obtained by trained research staff. Size for gestational age was calculated as the birthweight ratio (birth weight divided by mean birth weight for sex and gestational age). A birthweight ratio of less than 0.8 corresponds to $<10$ th centile. Because of the birthweight cut off $(<1850 \mathrm{~g})$ children born after 34 weeks' gestation all fell into this category and were therefore excluded from this study.

\section{Results}

Mean blood pressure was calculated for each of five birthweight categories. There was no trend in either systolic or diastolic blood pressure across the birthweight range or when regressed with birth weight as a continuous variable. Current weight was strongly positively associated with birthweight ratio $(p<0.001)$ and blood pressure $(p<0.001)$. After adjustment for current weight (mean (SD) $23.2(4.4) \mathrm{kg}$ ) or both weight and days of mechanical ventilation (median one day, 75 th and 95 th centile five and 18 days) and whether or not the $54(9 \%)$ neurologically impaired children were included, no association was found (table 1).

Blood pressure increased with increasing category of weight for gestational age. In a regression analysis there was a $0.47 \mathrm{~mm} \mathrm{Hg}$ increase in systolic $(p<0.02)$ and $0.39 \mathrm{~mm} \mathrm{Hg}$ increase in diastolic blood pressure $(p<0.01)$ for each 0.1 increase in birthweight ratio. After adjusting for current weight the trend to higher systolic pressure with increasing ratio was not statistically significant $(p<0 \cdot 2)$. For adjusted diastolic blood pressure the trend reached significance after excluding neurologically impaired children $(p<0.04$ whether or not adjusted for days of ventilation). Table 2 shows blood pressures unadjusted and adjusted as above.
Infant and Child

Nutrition Group, MRC Dunn Nutrition Unit, Cambridge

R Morley

G Lister

C Leeson-Payne

A Lucas

Correspondence to Dr Ruth Morley, 23 High Street, Great Shelford, Cambridge CB2 5EH.

Accepted 16 March 1994
Table 1 Blood pressure and birth weight

\begin{tabular}{|c|c|c|c|c|c|c|}
\hline \multirow[b]{2}{*}{$\begin{array}{l}\text { Birth weight } \\
\text { (g) }\end{array}$} & \multicolumn{3}{|c|}{ Mean systolic blood pressure $(\mathrm{mm} \mathrm{Hg})$} & \multicolumn{3}{|c|}{ Mean diastolic blood pressure $(\mathrm{mm} \mathrm{Hg})$} \\
\hline & $\begin{array}{l}\text { Unadjusted } \\
\text { (SD) }\end{array}$ & $\begin{array}{l}\text { Adjusted } \\
\text { for current } \\
\text { weight }\end{array}$ & $\begin{array}{l}\text { Adjusted for } \\
\text { weight and } \\
\text { ventilation }\left(n^{\star}\right)\end{array}$ & $\begin{array}{l}\text { Unadjusted } \\
(S D)\end{array}$ & $\begin{array}{l}\text { Adjusted } \\
\text { for current } \\
\text { weight }\end{array}$ & $\begin{array}{l}\text { Adjusted for } \\
\text { weight and } \\
\text { ventilation }\left(n^{\star}\right)\end{array}$ \\
\hline $\begin{array}{l}\leqslant 1000(n=86) \\
1001-1250(n=150) \\
1251-1500(n=156) \\
1501-1850(n=224)\end{array}$ & $\begin{array}{r}99 \cdot 1(9 \cdot 9) \\
101 \cdot 2(9 \cdot 8) \\
100 \cdot 5(9 \cdot 9) \\
100 \cdot 4(9 \cdot 4)\end{array}$ & $\begin{array}{r}99 \cdot 6 \\
100 \cdot 6 \\
100 \cdot 6 \\
100 \cdot 7\end{array}$ & $\begin{array}{c}99 \cdot 3(78) \\
100 \cdot 7(137) \\
100 \cdot 4(135) \\
101 \cdot 0(212)\end{array}$ & $\begin{array}{l}60 \cdot 7(8 \cdot 0) \\
60 \cdot 8(7 \cdot 2) \\
60 \cdot 8(7 \cdot 2) \\
60 \cdot 6(7 \cdot 4)\end{array}$ & $\begin{array}{l}60 \cdot 1 \\
60 \cdot 3 \\
61 \cdot 0 \\
61 \cdot 1\end{array}$ & $\begin{array}{l}60 \cdot 0(78) \\
60 \cdot 3(137) \\
60 \cdot 9(135) \\
61 \cdot 1(212)\end{array}$ \\
\hline
\end{tabular}

*Only neurologically normal children are included in these analyses. 
Table 2 Blood pressure and birthweight ratio

\begin{tabular}{|c|c|c|c|c|c|c|}
\hline \multirow[b]{2}{*}{$\begin{array}{l}\text { Birth weight } \\
\text { ratio }\end{array}$} & \multicolumn{3}{|c|}{ Mean systolic blood pressure ( $\mathrm{mm} \mathrm{Hg}$ ) } & \multicolumn{3}{|c|}{ Mean diastolic blood pressure $(\mathrm{mm} \mathrm{Hg})$} \\
\hline & $\begin{array}{l}\text { Unadjusted } \\
(S D)\end{array}$ & $\begin{array}{l}\text { Adjusted } \\
\text { for current } \\
\text { weight }\end{array}$ & $\begin{array}{l}\text { Adjusted for } \\
\text { weight and } \\
\text { ventilation }\left(n^{\star}\right)\end{array}$ & $\begin{array}{l}\text { Unadjusted } \\
\text { (SD) }\end{array}$ & $\begin{array}{l}\text { Adjusted } \\
\text { for current } \\
\text { weight }\end{array}$ & $\begin{array}{l}\text { Adjusted for } \\
\text { weight and } \\
\text { ventilation }\left(n^{\star}\right)\end{array}$ \\
\hline $\begin{array}{l}<0 \cdot 8(n=200) \\
0 \cdot 8-<0 \cdot 9(n=117) \\
0 \cdot 9-<1 \cdot 0(n=115) \\
1 \cdot 0-<1 \cdot 1(n=103) \\
\geqslant 1 \cdot 1(n=81)\end{array}$ & $\begin{array}{l}99.4(10.5) \\
100.0(8 \cdot 8) \\
101 \cdot 1(9 \cdot 5) \\
100 \cdot 7(9 \cdot 8) \\
102.3(9.0)\end{array}$ & $\begin{array}{r}100 \cdot 1 \\
99 \cdot 9 \\
101 \cdot 0 \\
100 \cdot 7 \\
101 \cdot 6\end{array}$ & $\begin{array}{c}99 \cdot 6(192) \\
99 \cdot 7(109) \\
101 \cdot 3(102) \\
101 \cdot 4(90) \\
102 \cdot 2(69)\end{array}$ & $\begin{array}{l}60 \cdot 1(7 \cdot 3) \\
60 \cdot 9(7 \cdot 4) \\
60 \cdot 0(7 \cdot 6) \\
61 \cdot 6(7 \cdot 0) \\
62 \cdot 0(7 \cdot 4)\end{array}$ & $\begin{array}{l}60 \cdot 5 \\
61 \cdot 0 \\
60 \cdot 9 \\
60 \cdot 8 \\
60 \cdot 7\end{array}$ & $\begin{array}{l}59 \cdot 8(192) \\
60 \cdot 9(109) \\
61 \cdot 1(102) \\
61 \cdot 3(90) \\
61 \cdot 7(69)\end{array}$ \\
\hline
\end{tabular}

*Only neurologically normal children are included in these analyses.

No other antenatal or neonatal factors (including toxaemia of pregnancy) were identified as influencing these associations and the findings were similar in singletons and children (19\%) from multiple pregnancies.

There was a positive association between head circumference at birth and systolic blood pressure $(p<0.05)$, though this was not found after adjusting for current head circumference. There was no association between blood pressure and body mass or ponderal indices, body length, or head circumference to length ratio at birth, either before or after adjustment for gestational age and sex.

Using the sphygmomanometer, systolic and diastolic blood pressures were slightly lower (by 3.6 and $1.2 \mathrm{~mm} \mathrm{Hg}$ respectively) than with the automated device. All these findings were independent of the method used, however.

\section{Discussion}

Reduced fetal growth, perhaps related to poor maternal nutrition, is believed to be a risk factor for later high blood pressure. ${ }^{12}$ In this study of children born before 34 weeks' gestation, however, we found that blood pressure at 7.5 to 8 years decreased with decreasing size for gestational age and a trend towards this 'reverse' relation was found even after adjusting for current weight. If reduced fetal growth programmes for higher blood pressure, our data suggest, perhaps surprisingly, that this process operates relatively late in gestation. If so, we might expect that postnatal nutrition of infants born preterm would be influential for later blood pressure and we are currently investigating this.
If reduced birth weight per se programmes for higher later blood pressure, ${ }^{3}$ then our data (birthweight range 663 to $1843 \mathrm{~g}$ ) could suggest a threshold birth weight below which there is no further influence. Unlike Law et al ${ }^{4}$ we did not find that low ponderal index at birth or a small head circumference was associated with increased later blood pressure; in contrast, a small head circumference at birth was associated with significantly lower unadjusted systolic blood pressure at $7 \cdot 5$ to 8 years.

It is possible that our observations could reflect an unusual pattern of development in infants born preterm. Adjustment for a range of markers of neonatal illness did not alter our findings, however, and exclusion of neurologically impaired children sharpened the 'reversed' relation. The association between early growth and later blood pressure is neither simple nor general. Further studies are required to determine whether and at which stage of pregnancy any public health interventions might influence birth weight or later blood pressure.

1 Law CM, de Swiet M, Osmond C, et al. Initiation of hypertension in utero and its amplification throughout life. BMF 1993; 306: 24-7.

2 Barker DJP, Gluckman PD, Godfrey KM, et al. Review; fetal nutrition and cardiovascular disease in adult life. Lancet 1993; 341: $938-41$.

3 Whincup PH, Cook DG, Papacosta O. Do maternal and intrauterine factors influence blood pressure in childhood? intrauterine factors influence blood

4 Law CM, Barker DJP,. Bull AR, Osmond C. Maternal and fetal influences on blood pressure. Arch Dis Child 1991; 66: 1291-5.

5 Lucas A, Gore SM, Cole TJ, et al. A multicentre trial on the feeding of low birthweight infants: effects of diet on early growth. Arch Dis Child 1984; 59: 722-30. 